Ralph M.H.G. Huits

Rosetta Bremmer

Roelien H. Enting

Herman G. Sprenger

Sander van Assen

\section{Return of meningeal symptoms in a patient treated for cryptococcal meningitis}

Received: 6 September 2006

Received in revised form: 5 December 2006

Accepted: 13 December 2006

Published online: 2 April 2007

Sirs: A 28-year-old Guinese man was admitted to our hospital with a 3-week history of severe headache, vomiting and fever. Ten months earlier he was diagnosed with AIDS. The presenting AIDS-defining illness then, was disseminated cryptococcosis: Cryptococcus neoformans had been recovered from CSF, bronchoalveolar washings, and blood. Standard treatment of $\mathrm{CM}$ with amphotericin B and flucytosine followed by fluconazole [1] resulted in clinical and microbiological cure. The patient had been taking fluconazole $200 \mathrm{mg}$ QD PO as secondary prophylaxis since. After successful treatment of CM, HAART was initiated. This

R.M.H.G. Huits · H.G. Sprenger

S. van Assen ( $\square)$

Dept. of Internal Medicine

Division of Infectious Diseases

University Medical Center Groningen

Postbus 30001

9700 RB Groningen

The Netherlands

Tel.: +31-50-3612350

Fax: +31-50-3619069

E-Mail: s.van.assen@int.umcg.nl

R. Bremmer - R. H. Enting

Dept. of Neurology, University Medical

Center Groningen, Groningen

The Netherlands preceded admission by 320 days. The CD4 cell count rose from 0 to 120 cells/ $\mu \mathrm{l}$ and HIV1-RNA to undetectable levels ( $<50$ copies/ $\mathrm{ml}$ ). There was no reason to doubt compliance to fluconazole prophylaxis.

On examination an ill-looking man was seen, with low-grade pyrexia and stable haemodynamics. He was alert and cooperative, with no signs of meningism or mental confusion. Neurological examination and further physical examination revealed no abnormalities. Laboratory results were unremarkable. Brain CT-scan without contrast did not show any mass lesions, or hydrocephalus. Clear CSF was obtained, opening pressure was $>50 \mathrm{~cm} \mathrm{H}_{2} \mathrm{O}$. CSF contained $0.59 \mathrm{~g} / \mathrm{l}$ protein, $3.0 \mathrm{mmol} / \mathrm{l}$ glucose (at a serum glucose concentration of $5.1 \mathrm{mmol} / \mathrm{l})$ and $272 \times 10^{6} / 1 \mathrm{leu}-$ kocytes, mainly monocytic. It tested positive for cryptococcal antigen. Considering relapse $\mathrm{CM}$, treatment appropriate to this diagnosis was initiated (amphotericin B $1 \mathrm{mg} / \mathrm{kg}$ intravenously per day and flucytosine $100 \mathrm{mg} /$ $\mathrm{kg} / \mathrm{d} \mathrm{PO}$ ).

After 1 week his headache and malaise had not improved. Both stain and culture were negative for Cryptococcus neoformans. Cryptococcal antigen titers were found to be low: $1: 16$ in serum and 1:4 in CSF. Therefore the diagnosis was revised to Cryptococcus neoformans-related immune reconstitution inflammatory syndrome (IRIS).

Antifungal treatment was discontinued and prednisone was prescribed ( $1 \mathrm{mg} / \mathrm{kg} /$ day IV).

One more lumbar puncture was needed for temporary relief of symptoms due to raised CSF pressure. Our patient made a dramatic recovery and was discharged from hospital 3 days later, symptom-free. Prednisone was tapered in 4 months.

IRIS can manifest itself as a latent infection unmasked by immune reconstitution, or as sterile inflammation in response to persisting antigens of an infection already treated. Therefore, latent infection should be ruled out in patients commencing antiretroviral therapy.

Key to the diagnosis of cryptococcal-related IRIS in patients treated with HAART is the absence of fungal cells in all cultures. Cryptococcal antigen in blood or CSF of HIV-infected patients previously treated for $\mathrm{CM}$, is a poor marker of infection [2]. Shelburne et al. found low cryptococcal antigen titres of value in discriminating cryptococcal-related IRIS from CM in a retrospective cohort study [3]. Other factors predictive of cryptococcal-related IRIS are a higher white blood cell count in CSF, higher CSF glucose and a higher CD4 cell count. . Lumbar puncture opening pressure was significantly higher in the IRIS group. These findings reflect the inflammatory nature of the syndrome due to immune restoration. The presence of the following risk factors for IRIS support the diagnosis in this case: a rise in CD4 cell count, a decrease in viral load, and compliance with a secondary prophylactic treatment regime of fluconazole.

For treatment of the aseptic meningitis, anti-inflammatory drugs are a logical choice. Shortterm corticosteroid administration was shown to be safe and well tolerated in patients who are receiving antiretroviral treatment [4]. It proved beneficial to prevent paradoxical reactions in tuberculous meningitis [5] and in other described cases of cryptococcal meningitis associated IRIS [6]. At a dose of $60 \mathrm{mg}$ prednisone IV, 
our patient responded well. However, studies defining the role of corticosteroids in IRIS are urgently needed. The use of corticosteroids was demonstrated to be harmful in CM or cryptococcoma [7]. Therefore, exclusion of active cryptococcal disease remains the most important step in managing Cryptococcus neoformans-related IRIS.

Guidelines for the treatment of $\mathrm{CM}$ recommend daily lumbar punctures in all patients with initially elevated opening pressures $\left(>25 \mathrm{~cm} \mathrm{H}_{2} \mathrm{O}\right.$ ) until the pressure is adequately controlled $[1,7]$. Since the mechanism for increased intracranial pressure is thought to be the same in CM and cryptococcal IRIS, adherence to these guidelines seems prudent.

Concluding, the HIV-positive patient treated with highly active antiretroviral therapy and returning meningeal symptoms after treatment for cryptococcal meningitis is diagnostically challeng- ing. Distinguishing between Cryptococcus neoformans-related IRIS and active cryptococcal disease as two different clinical entities is crucial.

\section{References}

1. Saag MS, Graybill RJ, Larsen RA, Pappas PG, Perfect JR, Powderly WG, Sobel JD, Dismukes WE (2000) Practice guidelines for the management of cryptococcal disease. Infectious Diseases Society of America. Clin Infect Dis 30:710-718

2. Powderly WG, Cloud GA, Dismukes WE, Saag MS (1994) Measurement of cryptococcal antigen in serum and cerebrospinal fluid: value in the management of AIDS-associated cryptococcal meningitis. Clin Infect Dis 18:789-792

3. Shelburne SA III, Darcourt J, White AC Jr., Greenberg SB, Hamill RJ, Atmar RL, Visnegarwala F (2005) The role of immune reconstitution inflammatory syndrome in AIDS-related Cryptococcus neoformans disease in the era of highly active antiretroviral therapy. Clin Infect Dis 40:1049-1052

4. McComsey GA, Whalen CC, Mawhorter SD, Asaad R, Valdez H, Patki AH, Klaumunzner J, Gopalakrishna KV,
Calabrese LH, Lederman MM (2001)

Placebo-controlled trial of prednisone in advanced HIV-1 infection. AIDS 15:321327

5. Thwaites GE, Nguyen DB, Nguyen HD, Hoang TQ, Do TT, Nguyen TC, Nguyen QH, Nguyen TT, Nguyen NH, Nguyen TN, Nguyen NL, Nguyen HD, Vu NT, Cao HH, Tran TH, Pham PM, Nguyen TD, Stepniewska K, White NJ, Tran TH, Farrar JJ (2004) Dexamethasone for the treatment of tuberculous meningitis in adolescents and adults. $\mathrm{N}$ Engl J Med 351:1741-1751

6. Venkataramana A, Pardo CA, McArthur JC, Kerr DA, Irani DN, Griffin JW, Burger P, Reich DS, Calabresi PA, Nath A (2006) Immune reconstitution inflammatory syndrome in the CNS of HIVinfected patients. Neurology 67:383-388

7. Graybill JR, Sobel J, Saag M, van Der HC, Powderly W, Cloud G, Riser L, Hamill R, Dismukes W (2000) Diagnosis and management of increased intracranial pressure in patients with AIDS and cryptococcal meningitis. The NIAID Mycoses Study Group and AIDS Cooperative Treatment Groups. Clin Infect Dis 30:47-54 